\title{
Cross-sectional study on prevalence and consequences of screen time on physical and mental health in children in the era of COVID-19
}

\author{
Neha Thakur (Rai) ${ }^{1}$, Arvind Kumar Singh², Narendra Rai ${ }^{3}$, Devesh Kumar Shukla ${ }^{4}$ \\ ${ }^{1}$ Assistant Professor, Department of Pediatrics, ${ }^{2}$ Additional Professor, Department of Community Medicine, Dr. Ram \\ Manohar Lohia Institute of Medical Science, ${ }^{3} \mathrm{MD}$ and Director, Department of Pediatrics, Chandan Hospital, ${ }^{4}$ Post \\ Graduate, Department of Statistics, University of Lucknow, Lucknow, Uttar Pradesh, India
}

Background: With the ongoing growth and expansion of digital media and COVID-19 pandemic, children are inclining more and more toward spending time on digital media as compared to outdoor sports, leading to poor physical and mental growth. Developed nations have already set up a screen time guideline which is yet to be established in developing nations. This study was conducted with the objectives of identifying the needs of screen time guidelines and to study the impact of screen time on mental and physical health in children. Aims and Objectives: This study aims to check the screen time in children aged 2-18 and find the health consequences both physical and psychological in those children. Materials and Methods: A cross-sectional study on children aged 2-18 years was conducted between 2019 and 2020. Parents were asked to fill a pre-structured questionnaire. Impact on health physical and mental were assessed by pediatrician and psychologist. Results: A total of 155 children were enrolled in the study. Mean child hours in children aged 2-5 years, 5-10 years, and $10-18$ years were $4 h, 5.83 h$, and $6.29 \mathrm{~h}$ on week days and $5.64 \mathrm{~h}$, $5.76 \mathrm{~h}$, and $7.69 \mathrm{~h}$ on weekends, respectively. More than one-third of children had age of onset of screen time below 2 years of age. About $70 \%$ of children had malnutrition. Only $18 \%$ of parents were aware of concept of screen free days. Screen time had negative impact on health $(P=0.0001)$ and on behavior of child $(P=0.001)$. Average increase in screen time during COVID-19 was nearly 3 times the pre-COVID era. Conclusion: This study has paved the way for the need of larger study and development of guidelines on impact of screen time on children in developing nations where screen time guidelines is yet to be set more so in era of COVID 19 pandemic.

Key words: Behavior; Children; COVID-19; Health; Screen time

\section{Access this article online}

Website:

http://nepjol.info/index.php/AJMS DOI: 10.3126/ajms.v13i1.40578

E-ISSN: 2091-0576

P-ISSN: 2467-9100

Copyright (c) 2022 Asian Journal of Medical Sciences

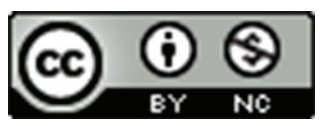

This work is licensed under a Creative Commons Attribution-NonCommercial 4.0 International License.

\section{INTRODUCTION}

The duration of time spent on electronic or digital media (such as television, smartphones, computer, tablets, gaming consoles, etc.) is defined as screen time. ${ }^{1}$ Rapid commercial expansion as well as changes in standard of living are shoving children from outdoor physical activities toward indoor mobile games resulting in amplified screen time. This has played an important role play in causing non-communicable diseases in children. ${ }^{2}$ The next decade will see a rise in noncommunicable diseases with its occurrence at an earlier age compared to the present decade. Increased and unregulated screen time will be one of the most important contributors to it. The American Academy of Pediatrics (AAP) guidelines has recommended $<1 \mathrm{~h} /$ day of screen time in children $<5$ years with no exposure to screen time in children $<2$ years. ${ }^{3}$ Even above 5 years, the duration of screen time recommended in children is to be $<2$ years. These guidelines

Address for Correspondence:

Dr. Neha Thakur (Rai), Assistant Professor, Department of Pediatrics, Dr. Ram Manohar Lohia Institute of Medical Science, Gomti Nagar, Lucknow - 226 010, Uttar Pradesh, India. Mobile: +91-7607804654. E-mail: nehaimsbhu@gmail.com 
come from world's most developed nation where awareness of parents regarding screen time is comparatively better than developing and under developed nations. Until now, no such guidelines have been developed in India. ${ }^{4}$ India is becoming one of the fastest consumers of digital media. ${ }^{3}$ Over the last century, there has been an explosion of digital technology with increasing access to digital media use both in rural and urban areas. Hence, this is the most appropriate time that we must set guidelines on screen time and increase awareness of parents and children regarding duration of screen time. With kids getting older excessive screen time be it any form (smartphones, tablets, laptops, television, and game consoles) would lead to interference in outdoor activities, education and playing with friends or spending quality time with family. As the screen time increases, physical activity would decrease leading to obesity and early onset diabetes and hypertension. This would increase the expenditure on health. COVID-19 caused by the novel coronavirus severe acute respiratory syndrome coronavirus- 2 is the most important health calamity of the century and the greatest challenge that humankind faced since the II-World War world wise strict lockdown was enforced. This pushed children from school teaching to online teaching. Thus, their screen time further escalated in proportions beyond imaginations. The impact of it on physical and mental health is yet to be assessed. Thus, this study was conducted with the objectives of assessing the average screen time in pre- and post-COVID era and to assess its impact on both physical and mental health. At present, there are no guidelines on duration of screen time in children of any age group in majority of developing nations. The present research helps us to set up the platform for providing guidelines on screen time which is a neglected area of child's health. The current world scenario requires it even more for the betterment of child's future.

\section{Aims and objectives}

This study aims to check the screen time in children aged 2-18 and find the health consequences both physical and psychological in those children.

\section{MATERIALS AND METHODS}

\section{Study design: (Pillot study)}

A cross-sectional study on children aged 2-18 years in capital city of India's most populous state was conducted between 2019 and 2020. The study was pre-approved by the Institutional Ethics Committee (IEC) for the final permission. After obtaining the permission of IEC, the study was conducted.

\section{Study participants \\ Inclusion criteria}

Healthy students aged 2 years -18 years whose parents or caregivers were willing to participate.

\section{Exclusion criteria}

Parents who refused to give consent, their children were excluded from the study.

Approvals from institute research committee and institute ethical committee were obtained.

\section{Definitions used in the study}

- Screen time: Duration of time spent on electronic or digital media such as television, smartphones, computer, tablets, gaming consoles, and iPad. ${ }^{1}$

- Malnutrition: Child malnutrition is defined as a pathological state resulting from either inadequate intake of energy or nutrients (protein-energy malnutrition) or due to excessive intake of energy (overweight and obesity). ${ }^{5}$

- Protein energy malnutrition (PEM): The WHO has defined PEM as an imbalance between the supply and demand of protein and energy for optimal growth and development. ${ }^{6}$

- Overweight: Child is termed overweight if the BMI is $\geq 85^{\text {th }}$ percentile but $<95^{\text {th }}$ percentile of the WHO growth charts for age and sex. ${ }^{7}$

- Obese: Child is termed obese if the BMI is $\geq 95^{\text {th }}$ percentile of the WHO growth charts and morbidly obese if the BMI is $\geq 120 \%$ of the $95^{\text {th }}$ percentile or $\geq 35 \mathrm{~kg} / \mathrm{m}^{2}$ (WHO growth charts). ${ }^{7}$

\section{Study tool}

Pre-structured questionnaire was filled by parents/ caregivers that gathered information on digital media use in children. The child weight and height were used to interpret the nutritional status as normal or malnutrition based on the WHO growth charts. ${ }^{8}$ Data regarding age, gender, and class of the child, parental education and occupation, time spent on screen both during week days and weekends of children and their parents, age of onset of screen time, and the most common gadget used were collected. We collected data on parental knowledge, behavior, and attitude toward screen time as well. They were asked on their knowledge regarding duration of screen time, concept of screen free days, restriction on nighttime use, and their attitude toward use of gadgets. We assessed the impact of restriction of gadget use on the behavior of children. We also collected data regarding impact of screen time on their behavior, sleep time, and overall health. The socioeconomic status of the family was calculated using the modified Kuppuswamy scale, revised for 2017. This tool is validated for our country. ${ }^{9}$ Parents were also enquired on average screen time in pre- and post-COVID era.

\section{Statistical analysis}

Statistical Package for the Social Sciences (SPSS version 20) will be used for data analysis. The Chi-square test will be 
used to compare qualitative variables, and the correlation between the quantitative variables will be carried out with the aid of the coefficient $r$ of Pearson. As it was a pilot study, sample size was not calculated.

\section{RESULTS}

A total of 155 children were included in the study after parental consent. Age and gender distribution of study participants are shown in Figure 1. Twenty-nine children (17 males and 12 females) belonged to $2-5$ years age group. Seventy-two children (43 males and 29 females) belonged to $5-10$ years. Fifty-four children (34 males and 20 females) belonged to $10-18$ years.

Mean child hours of daily screen time in weekdays versus weekends are shown in Figure 2. Mean screen time of children aged 2-5 years was nearly $4 \mathrm{~h}$ during weekdays and $5.64 \mathrm{~h}$ on weekends. Mean screen time of children aged 5-10 years was $5.83 \mathrm{~h}$ on weekdays and $5.76 \mathrm{~h}$ on weekends. For children aged 10-18 years, screen time was $6.29 \mathrm{~h}$ on weekdays and $7.69 \mathrm{~h}$ on weekends. Frequency of use of gadgets is shown in Figure 3.

The most common gadgets used were mobiles followed by television and laptop. Majority of children were sharing their gadgets with parents or siblings.

Age of onset of screen time is shown in Figure 4. Fiftythree children $(34 \%)$ had their onset of screen time below 5 years. Earliest age of onset of screen time was 3 months. Impact of screen time on health (physical and mental) and school performance is shown in Figures 5 and 6. About $59 \%$ of children had excellent academic performance. Only $30 \%$ of children were healthy. About $25.8 \%$ were malnourished, $14.2 \%$ were overweight, and $29.7 \%$ were obese. One hundred and twenty-nine children had abnormal behavior on withholding screen time. About $77 \%$ of parents were using screen time to feed children. Mean parental screen time was $5.02 \mathrm{~h}$. About $72.25 \%$ of

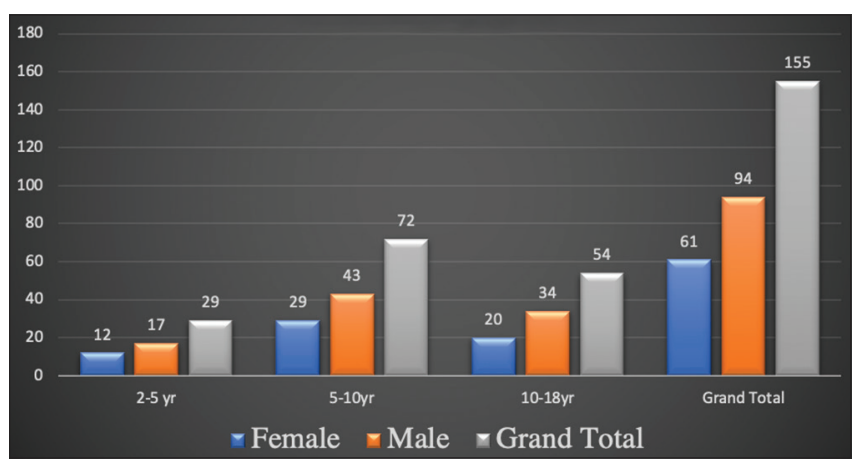

Figure 1: Age and gender of study participants children preferred screen time to physical activity. About $52 \%$ of parents felt that their children were addicted to screen time. About $37 \%$ of parents encouraged screen time for educational purposes. About 21\% of children had eyerelated complications due to excessive use of screen time.

Mobile phones were the most common gadget used in children aged $<5$ years $(\mathrm{P}=0.006)$. Handheld games $(\mathrm{P}=0.005)$ and laptops $(\mathrm{P}=0.004)$ were contributing significantly to screen time in children aged 5-10 years. Mobiles (0.000) and laptops (0.0006) were the most common gadgets which had significantly increased screen time in children aged $10-18$ years.

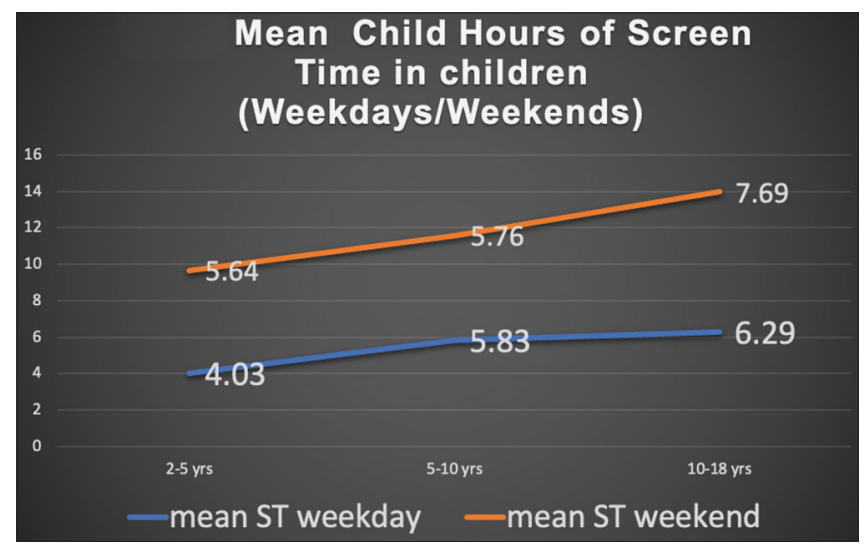

Figure 2: Mean screen time of children in weekends and week days

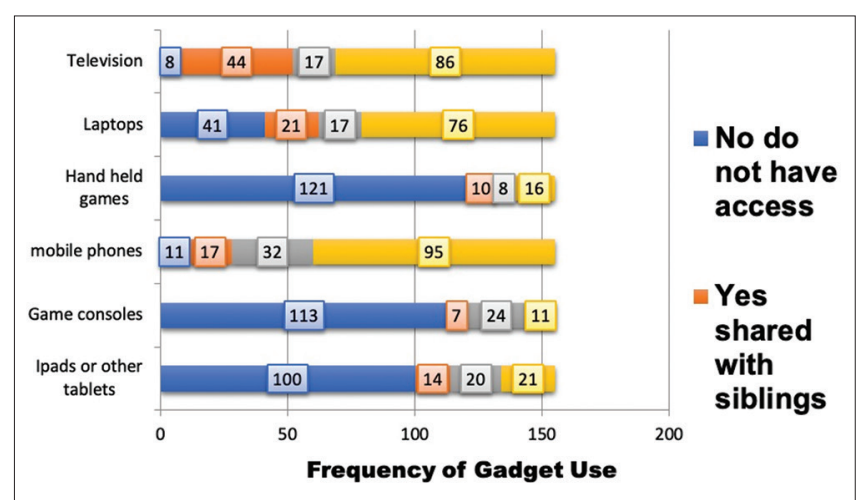

Figure 3: Frequency of gadget use in children

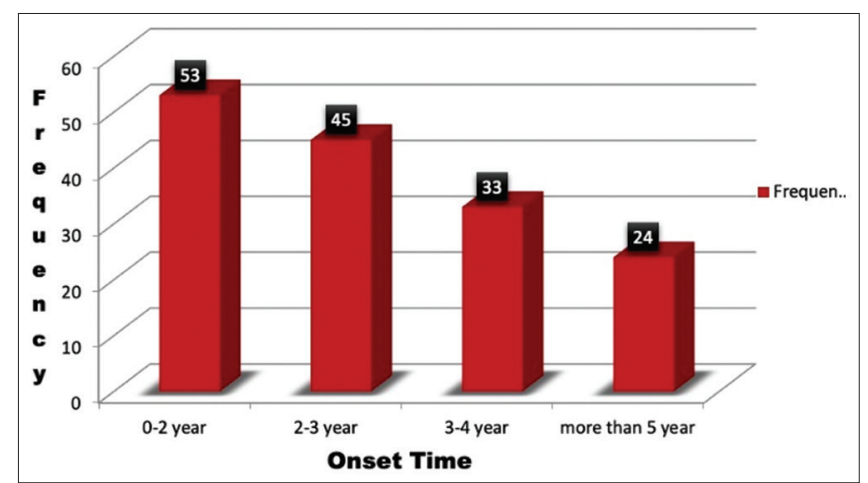

Figure 4: Age of onset of screen time in children 


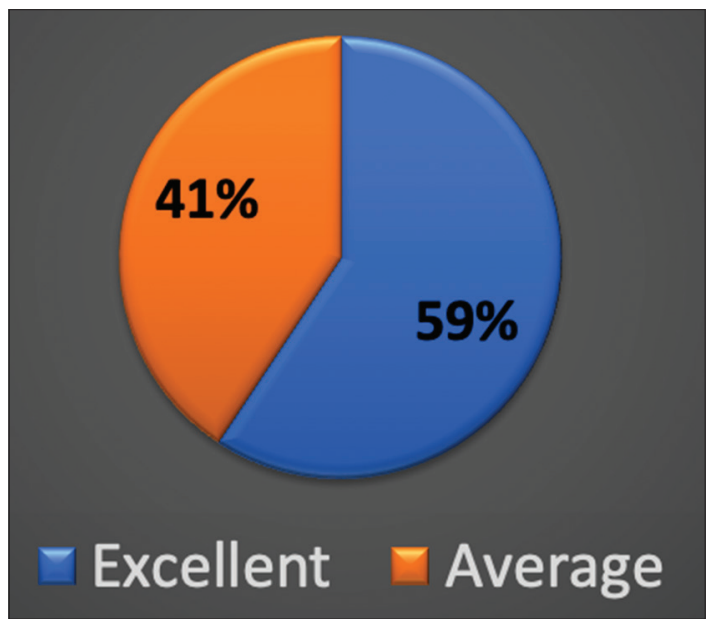

Figure 5: Impact of screen time on child school performance

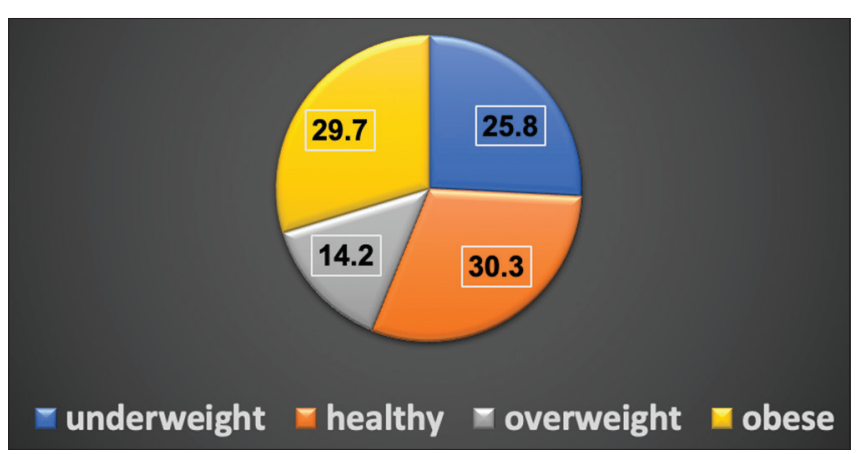

Figure 6: Impact of screen time on child nutritional status

Screen time had negative impact on health $(\mathrm{P}=0.0001)$ and on behavior of child $(\mathrm{P}=0.001)$. Screen time increased by manifolds of 10 times to that before the pandemic. Average increase in per day duration of screen time in children $<5$ years was $3 \mathrm{~h}$ children aged $5-10$ was $5 \mathrm{~h}$ and $>5 \mathrm{~h}$ increase was noticed in children above 10 years of age.

\section{DISCUSSION}

World over studies were conducted to study the impact of screen time on children's health. Studies have shown that excessive screen time is linked with sedentary habits, leading to obesity. ${ }^{10-12}$ High screen time was found to be associated with mood changes and developmental delay in children., ${ }^{3,13-15}$ These concerns lead AAP to formulate guidelines in 2016 for screen exposure. ${ }^{3}$ The WHO too realized the impact screen time can have on children hence released guidelines on keeping screen time $<1 \mathrm{~h}$ in children aged $2-4$ years. ${ }^{16}$ Following its footsteps, Canada too in 2017 formulated guidelines for screen time in children. ${ }^{17}$ Even in our neighboring country, China studies have found that high screen time is associated with sedentary habits and behavioral risk factors. ${ }^{18}$ Although one-fourth of world's children are in India, ${ }^{19}$ only 15 studies are there on screen time with only four studies focusing on children $<5$ years. ${ }^{20-22}$ Only one study is available from Uttar Pradesh. ${ }^{23}$ Impact of screen time on the development of children aged 2-5 years was done in southern state of Kerala. ${ }^{24}$ Another study was done in Tamil Nadu to find out the average daily duration of screen time in children aged $2-5$ years. ${ }^{25}$ Both in North and South India, duration of screen time crossed the recommended level in majority of children $(>80 \%) .^{24,25}$ In our study, $84 \%$ of children aged 2-5 years were having screen time more than $1 \mathrm{~h}$. Mean screen time of children in this age group was $4 \mathrm{~h}$ on week days and $5.64 \mathrm{~h}$ on weekends. Hence, children in this tender age group were having screen time 4-5 times that of recommended level. In our study, screen time was nearly double that found in the previous studies. ${ }^{23,24}$ This could be due to lesser number of children. In India, majority of studies were focused on children aged $<5$ years. We tried to encompass the whole pediatric age group and compare the screen time in preschool, midschool, and high school children. Majority of our study children belonged to 5-10 years. The problem of screen time is not just limited to developmental outcomes. It has a much wider impact as far as health (both physical and mental) and overall growth and development of child is concerned. In our study, we found that as age advances, the mean duration of screen time increases by leaps and bounds. It is $5.83 \mathrm{~h}$ in children aged 5-10 years and $6.29 \mathrm{~h}$ in children above 10 years on weekdays. On weekends, it increases to $5.76 \mathrm{~h}$ and $7.69 \mathrm{~h}$ in children aged 5-10 years and above 10 years, respectively. Thus above 5 years, the mean screen duration is roughly 5-7 times that of recommended level. On weekends, mean screen duration increases by more than an hour in children above 10 years. The most common gadget used were mobile phones, followed by television, laptops, pads or tablets, game consoles and handheld games. With increasingly available gadgets and with significantly improving network conditions and without parental guidance, we are facing another global health hazard as far as screen time is concerned. About $53 \%$ of children had their onset of screen time before 2 years of age. Guidelines have already mentioned that no child $<2$ years should have any form of screen time. ${ }^{3}$ Only one-third of study population were healthy. Nearly $70 \%$ of children had malnutrition. With nearly $30 \%$ being obese, $25.8 \%$ were underweight and $14.2 \%$ were overweight. Studies have shown marked irrefutable associations between increasing screen time and adiposity in childhood. ${ }^{25}$ As the screen time increase, there is decreased physical activity and tendency to consume high calorie food resulting in overweight and obesity. The systematic review of sedentary behavior and health indicators in children had found a positive correlation with hours of screen time and obesity. They had concluded that watching TV for more than $2 \mathrm{~h} /$ 
day was associated with unfavorable body composition. ${ }^{25}$ Obesity is becoming a serious health hazard in children both in developing and developed nations leading to early age of onset of chronic illness like hypertension diabetes 22 million children $<5$ years are obese and nearly one in 10 children are overweight. ${ }^{26}$ Impact of screen time on academic excellence was less marked in our study with more than $50 \%$ of study children having good academic record. The impact of screen time on academic performance did not match with the findings of a systematic review done to study impact of screen time on academic performance. They had found negative impact on academics with increasing screen time. ${ }^{27}$ This could be due to small sample and short duration of the study. About $21 \%$ of children had irritation of eyes with redness due to prolonged screen time. About $83 \%$ of children responded with abnormal behavior (angry, sad, frustrated, disappointed, frustrated, or complaining) on withholding gadget viewing. More than half of study parents $(52 \%)$ were bothered that their children were addicted to screen time and it is their favorite activity during free time. Hence besides physical health, screen time has negative impact on mental health as well. While evaluating parental knowledge and awareness on duration of screen time, concept of screen free days, we found that $18 \%(n=29)$ were aware of concept of screen free days. Mean parental screen time in our study is $5 \mathrm{~h}$. More than two-thirds of parents (77\%) took help of screen viewing to feed their children. In our study, $67 \%$ of parents were employed and were spending less time with children. More than one-third of parents (37\%) were encouraging screen time as they felt that it helps in education and keeps their children away from troubles. A working group of screen media and parenting researchers had identified and prioritized problems in evaluating screen media parenting practices. ${ }^{26} \mathrm{AAP}$ had recommended four types of parental supervision, namely, active supervision, coviewing, restricting time spent on screen, and restricting the content. ${ }^{27}$ In our study, majority of parents lacked the concept of parental supervision, restriction of time spent on screen time, or restriction of content. Hence there, is urgently a need of guidelines on optimal duration of screen time in children along with parental supervision. To the best of our knowledge, no study has been done till now to assess the impact of screen time on children in COVID-19.

\section{Limitations of the study}

This study was a pilot study with participants coming from a particular demographic profile.

\section{CONCLUSION}

Screen viewing is having negative impact on physical and mental health of children, leading to malnutrition, abnormal behaviors, screen addiction, ophthalmologic problems, and headache decreased interaction with peers. Parental supervision both active and passive is lacking. ${ }^{28,29}$ This pilot project confirms the need of larger studies from different parts of the country both urban and rural. These studies will help in formulating guidelines on screen time, particularly in the era of pandemic when majority of schools have closed down.

\section{ACKNOWLEDGMENT}

Parents who participated in the study.

\section{REFERENCES}

1. Barber SE, Kelly B, Collings PJ, Nagy L, Bywater T and Wright J. Prevalence, trajectories, and determinants of television viewing time in an ethnically diverse sample of young children from the UK. Int J Behav Nutr Phys Act. 2017;14(1):88-99.

https://doi.org/10.1186/s12966-017-0541-8

2. Kourlaba G, Kondaki K, Liarigkovinos $T$ and Manios $Y$. Factors associated with television viewing time in toddlers and preschoolers in Greece: The GENESIS study. J Public Health. 2009;31(2):222-230.

https://doi.org/10.1093/pubmed/fdp011

3. Chassiakos YL, Radesky J, Christakis D, Moreno MA, Cross $\mathrm{C}$ and Council on Communications and Media. Children and adolescents and digital media. Pediatrics. 2016;138(5):e20162593.

https://doi.org/10.1542/peds.2016-2593

4. Available from: https://www.mckinsey.com/ /media/mckinsey/ business/functions/mckinsey/digital/ourinsights/digital-indiatechnology-to-transform-a-connected-nation-in-brief.ashx [Last accessed on 2020 Mar 31].

5. Ge KY and Chang SY. Definition and measurement of child malnutrition. Biomed Environ Sci. 2001;14(4):283-291.

6. Onis MD and Blossner M. WHO Global Database on Child Growth and Malnutrition. Geneva: WHO; 1997. Available from: http://www.whqlibdoc.who.int/hq/1997/who_nut_97.4.pdf [Last accessed on 2010 Oct 01].

7. Styne DM, Arslanian SA, Connor EL, Farooqi IS, Murad MH, Silverstein $\mathrm{JH}$, et al. Pediatric obesity-assessment, treatment, and prevention: An endocrine society clinical practice guideline. J Clin Endocrinol Metab. 2017;102(3):709-757.

https://doi.org/10.1210/jc.2016-2573

8. WHO Multicentre Growth Reference Study Group. WHO child growth standards based on length/height, weight and age. Acta Paediatr Suppl. 2006;450:76-85.

https://doi.org/10.1111/j.1651-2227.2006.tb02378.x

9. Modified Kuppuswamy Scale; 2020. Available from: http://www. inatepsm.com/blog/modified-kuppuswamy-scale [Last accessed on 2020 Dec 17].

10. Marsh S, Ni Mhurchu $C$ and Maddison R. The non-advertising effects of screen-based sedentary activities on acute eating behaviours in children, adolescents, and young adults. A systematic review. Appetite. 2013;71:259-273. https://doi.org/10.1016/j.appet.2013.08.017

11. Gebremariam MK, Chinapaw MJ, Bringolf-Isler B, Bere E, Kovacs $\mathrm{E}$, Verloigne $\mathrm{M}$, et al. Screenbased sedentary time: 
Association with soft drink consumption and the moderating effect of parental education in European children: The ENERGY study. PLoS One. 2017;12(2):e0171537.

https://doi.org/10.1371/journal.pone.0171537

12. Klesges RC, Shelton ML and Klesges LM. Effects of television on metabolic rate: Potential implications for childhood obesity. Pediatrics. 1993;91(2):281-286.

13. Domingues-Montanari S. Clinical and psychological effects of excessive screen time on children. J Paediatr Child Health. 2017;53(4):333-338.

https://doi.org/10.1111/jpc.13462

14. Brunetti VC, O'Loughlin EK, O'Loughlin J, Constantin E and Pigeon E. Screen and nonscreen sedentary behavior and sleep in adolescents. Sleep Health. 2016;2(4):335-340.

https://doi.org/10.1016/j.sleh.2016.09.004

15. Lee EY, Hunter S, Leatherdale ST and Carson V. Sociodemographic correlates of physical activity and screen time among adolescents in Canada and Guatemala: Results from the COMPASS system. Glob Health Promot. 2019;26(2):25-35 https://doi.org/10.1177/1757975917710804

16. WHO Guidelines on Physical Activity, Sedentary Behavior and Sleep for Children Under 5 Years of Age; 2019. Available from: https://www.who.int/news/item/24-04-2019-to-grow-up-healthychildren-need-to-sit-less-and-play-more. [Last accessed on 2020 Aug 24]

17. Canadian Paediatric Society, Digital Health Task Force, Ottawa, Ontario. Screen time and young children: Promoting health and development in a digital world. Paediatr Child Health. 2017;22(8):461-477.

https://doi.org/10.1093/pch/pxx123

18. Wang $\mathrm{H}$, Zhong J, Hu R, Fiona B, Yu M and Du H. Prevalence of high screen time and associated factors among students: A cross-sectional study in Zhejiang, China. BMJ Open. 2018;8(6):e021493.

https://doi.org/10.1136/bmjopen-2018-021493

19. UNICEF. The State of the World's Children 2016: A Fair Chance For Every Child. Geneva: UNICEF; 2016. Available from: https:// www.unicef.org/publications/files/unicef_sowc_2016.pdf [Last accessed on 2018 Dec 30].

20. Sampasa-Kanyinga $H$, Standage $M$, Tremblay MS, Katzmarzyk PT, Hu G, Kuriyan R, et al. Associations between meeting combinations of 24-h movement guidelines and health-related quality of life in children from 12 countries. Public Health. 2017;153:16-24.

https://doi.org/10.1016/j.puhe.2017.07.010

21. Saxena R, Vashist P, Tandon R, Pandey RM, Bhardawaj A,
Gupta V, et al. Incidence and progression of myopia and associated factors in urban school children in Delhi: The North India myopia study (NIM Study). PLoS One. 2017;12(12):e0189774.

https://doi.org/10.1371/journal.pone.0189774

22. Bapat R, van Geel M and Vedder P. Socio-Economic Status, Time spending, and sleep duration in Indian children and adolescents. J Child Fam Stud. 2017;26(1):80-7.

https://doi.org/10.1007/s10826-016-0557-8

23. Shah RR, Fahey NM, Soni AV, Phatak AG and Nimbalkar SM. Screen time usage among preschoolers aged 2-6 in rural Western India: A cross-sectional study. J Family Med Prim Care. 2019;8(6):1999-2002.

https://doi.org/10.4103/jfmpc.jfmpc_206_19

24. John JJ, Joseph R, David A, Bejoy A, George KV and George L. Association of screen time with parent-reported cognitive delay in preschool children of Kerala, India. BMC Pediatr. 2021;21:73. https://doi.org/10.1186/s12887-021-02545-y

25. Tremblay MS, LeBlanc AG, Kho ME, Saunders TJ, Larouche R, Colley RC, et al. Systematic review of sedentary behaviour and health indicators in school-aged children and youth. Int J Behav Nutr Phys Act. 2011;8:98.

https://doi.org/10.1186/1479-5868-8-98

26. WHO. Preventing Chronic Diseases: A Vital Investment. Geneva: WHO; 2015. Available from: http://www.who.int/chp/ chronic_disease_report/en [Last accessed on 2014 Mar 04].

27. Adelantado-Renau M, Moliner-Urdiales D, CaveroRedondo I, Beltran-Valls MR, Martínez-Vizcaíno $\mathrm{V}$ and Álvarez-Bueno C. Association between screen media use and academic performance among children and adolescents: A systematic review and meta-analysis. JAMA Pediatr. 2019;173(11):1058-1067.

https://doi.org/10.1001/jamapediatrics.2019.3176

28. O'Connor TM, Hingle M, Chuang RJ, Gorely T, Hinkley T, Jago $R$, et al. Conceptual understanding of screen media parenting: Report of a working group. Child Obes. 2013;9 Suppl 1:S110-S118.

https://doi.org/10.1089/chi.2013.0025

29. Gentile DA, Reimer RA, Nathanson Al, Walsh DA and Eisenmann JC. Protective effects of parental monitoring of children's media use: A prospective study. JAMA Pediatr. 2014;168(5):479-484.

https://doi.org/10.1001/jamapediatrics.2014.146

\footnotetext{
Authors' Contributions:

NT and NR - Concept and design of the study, prepared first draft of manuscript; AKS and DKS - Interpreted the results; reviewed the literature and manuscript preparation; NT, AKS, DKS, and NR - Concept, coordination, statistical analysis and interpretation, preparation of manuscript, and revision of the manuscript.

Work attributed to:

Dr. Ram Manohar Lohia Institute of Medical Science, Gomti Nagar, Lucknow, Uttar Pradesh, India.

ORCID ID:

Dr. Neha Thakur (Rai)- (1) https://orcid.org/0000-0003-2374-7740

Dr. Arvind Kumar Singh- (1) https://orcid.org/0000-0001-9153-6641

Dr. Narendra Rai- (1) https://orcid.org/0000-0003-0979-2377

Mr. Devesh Kumar Shukla- (1) https://orcid.org/0000-0002-2719-9705

Source of Funding: None, Conflicts of Interest: None.
} 